\title{
Research on the Effects of Light Intensity and Seeding Density on the Seed Germination and Seedling Growth of Liriodendron chinense
}

\author{
Weixing Xue, Qiuju Guo*, Jiang Zhu, Juyang Wu, Yangxiang Huang, Lieyao Deng \\ School of Forestry and Horticulture, Hubei Minzu University, Enshi, China \\ Email: 1290529342@qq.com, ^724185298@qq.com, 1243006706@qq.com,2017052@hbmzu.edu.cn, 1579049074@qq.com, \\ 577998654@qq.com
}

How to cite this paper: Xue, W.X., Guo, Q.J., Zhu, J., Wu, J.Y., Huang, Y.X. and Deng, L.Y. (2022) Research on the Effects of Light Intensity and Seeding Density on the Seed Germination and Seedling Growth of Liriodendron chinense. Journal of Agricultural Chemistry and Environment, 11, 24-41

https://doi.org/10.4236/jacen.2022.111003

Received: December 14, 2021

Accepted: January 27, 2022

Published: January 30, 2022

Copyright $\odot 2022$ by author(s) and Scientific Research Publishing Inc. This work is licensed under the Creative Commons Attribution International License (CC BY 4.0).

http://creativecommons.org/licenses/by/4.0/

(c) (i) Open Access

\begin{abstract}
It provides a theoretical basis for the artificial promotion of the reproduction and regeneration of Liriodendron chinense through exploring the effects of light intensity and seeding density on the seed germination and seedling growth of this rare plant. Controlled experiments were conducted by setting different seeding densities and shading intensities to observe and detect the seed germination and seedling growth under different experimental conditions. The data were analyzed by SPSS and the model was fitted to calculate the seed germination rate, seedling emergence rate and seedling growth parameters of Liriodendron chinense, which were used to analyze the effects of seeding density and light intensity on the seed germination and seedling growth of Liriodendron chinense. Light has a significant impact on the seed germination and seedling growth of Liriodendron chinense $(P<0.01)$, while seeding density has no remarkable effect on the same $(P>0.05)$. High density promotes the seedling height (the seedling height showed a rising trend with the increase of seeding density, reaching the highest at 500 seeds $/ \mathrm{m}^{2}$. "3-stitch

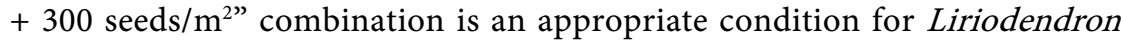
chinense reproduction since it can realize higher germination rate and better seedling growth potential. The seedling height and basal diameter growth curve of Liriodendron chinense fits well to the Logistic equation $\left(R^{2} \geq 0.977\right)$. Light has a significant impact on the seed germination and seedling growth of Liriodendron chinense, and appropriate shading treatment can increase the seed germination rate and seedling emergence rate of Liriodendron chinense. Seeding density has little influence on the seed germination rate of Liriodendron chinense, but high density will promote seedling height.
\end{abstract}

\section{Keywords}

Liriodendron chinense, Light, Density, Seed Germination, Seedling Growth 


\section{Introduction}

Liriodendron chinense, an arbor species of Liriodendron in Magnoliaceae, is an ancient relic plant and one of the unique, rare and endangered species in China. In the long natural succession, natural forests of Liriodendron chinense are limited to Guizhou, Hubei, Hunan, Chongqing, Sichuan and other areas south of the Yangtze River [1] due to the endangering habitats, fierce interspecific competition within natural communities, low seed vitality and parthenogenesis, heavy deforestation and other reasons [2]. The natural regeneration of natural populations faces great obstacles, and the normal reproduction and regeneration is the basis for the sustainability of the populations, and is crucial to maintain the stability and normal succession of natural forest communities. For various reasons, the number of wild Liriodendron chinense is decreasing. Therefore, Chinese experts and scholars have carried out a lot of research to explore the reproduction and regeneration law of this population, hoping to offer a theoretical basis for facilitating the protection of this species. Sexual reproduction [3] [4] [5] [6], asexual reproduction [7] [8] and genetic characteristics [9] [10] of Liriodendron chinense have been studied. However, according the practical investigation, there are few naturally regenerated Liriodendron chinense seedlings or saplings in the natural forests of Liriodendron chinense. Seedlings are occasionally seen on the exposed land in the forest gaps. Seed germination and seedling establishment are the most fundamental steps in the process of plant growth and development, and are subject to many factors. Previous research on seed germination and seedling establishment mainly focused on the influence of external factors, such as environmental factors of temperature, moisture and sunlight [11] [12] [13] [14] [15], storage mode and time, and dormancy breaking technology. Therefore, this study, by simulating the habitat conditions of Liriodendron chinense natural forests, discusses the factors facilitating seed germination and seedling growth, which is significant for the natural regeneration of $L i$ riodendron chinense.

\section{Material and Methods}

\subsection{Experimental Materials}

In October 2019, several mother trees of Liriodendron chinense, which are healthy, free of diseases and insect pests, and clustered, were selected from the natural forest sample plot of Liriodendron chinense for seed collection according to the Synopsis of Technical Standards for Collecting Seeds from Wild Plants by Cai Jie et al. [16]. The seedballs collected were naturally air dried until the seeds completely fell off from the seedballs, which were stored in a refrigerator $\left(-5^{\circ} \mathrm{C}\right)$ for later usage.

In March 2020, a flat land (E108 $\left.57^{\prime} 12.25^{\prime \prime}, \mathrm{N} 30^{\circ} 15^{\prime} 40.99^{\prime \prime}\right)$ in Lichuan Institute of Forestry Science, Enshi Tujia and Miao Autonomous Prefecture, Hubei Province was selected as the experimental land, which is located in an area with similar habitat conditions (annual average temperature, precipitation, altitude 
and others) to the investigated Liriodendron chinense natural forest.

\subsection{Experimental Methods}

\subsubsection{Seeding Simulation Experiment}

In December 2019, the stored Liriodendron chinense seeds were soaked in 50\% carbendazim for disinfection, mixed with wet sand for lamination at the normal temperature, and stirred once a week. During this process, the water content was observed and maintained.

Referring to the canopy density of the natural forest measured during the investigation and the sunshade net density commonly used in field experiments, 5 light intensity gradients of CK, 2-stitch, 3-stitch, 4-stitch and 6-stitch, and 5 seeding density gradients of 100 seeds $/ \mathrm{m}^{2}, 200$ seeds $/ \mathrm{m}^{2}, 300$ seeds $/ \mathrm{m}^{2}, 400$ seeds $/ \mathrm{m}^{2}$ and 500 seeds $/ \mathrm{m}^{2}$ were set in this experiment, with 3 repetitions for each treatment. The experimental land was weeded, leveled, ridged and furrowed, with a ridge width of $1 \mathrm{~m}$. The experimental field was sterilized with $50 \%$ carbendazim, and the ridge surface was divided into $1 \mathrm{~m} \times 1 \mathrm{~m}$ squares. The seeds were evenly sown in the squares at the seeding densities set, covered with even fine earth to the extent that they were just buried, and then watered with a sprinkling can, followed by natural control and shading treatment with 2 -stitch, 3-stitch, 4-stitch and 6-stitch sunshade nets. After shading treatment, the shading coefficients were measured at different times (9:00, 12:00 and 17:00) under different weather conditions (sunny, cloudy and rainy), and averaged to get the shading coefficients of sunshade nets with different specifications (Table 1). In this paper, the shading intensity was represented by the stitch specification of the sunshade nets.

The seeds were observed frequently after sowing and the number of sprouted seeds was recorded from the day of the first germination. The seeds were then observed every 7 days and the germination rate was calculated when the germination was completed. The emerged seedlings were observed and measured every 30 days. In each sample square, 10 labeled seedlings were selected for observation and recording of the height with a steel tape, and the basal diameter with a vernier caliper. The investigation ended in December 2020, when all the seedlings entered the dormancy period with leaves fallen.

\subsubsection{Data Processing and Analysis}

Origin 2017 was used to fit the growth rhythm data of seedling height and basal

Table 1. Shading rate of shade nets with different densities.

\begin{tabular}{cccccc}
\hline & CK & 2 Needle & 3 Needle & 4 Needle & 6 Needle \\
\hline Sunny & 0 & $57.13 \%$ & $68.67 \%$ & $77.34 \%$ & $88.56 \%$ \\
Cloudy & 0 & $51.85 \%$ & $59.45 \%$ & $75.31 \%$ & $86.45 \%$ \\
Rainy & 0 & $53.25 \%$ & $64.75 \%$ & $72.97 \%$ & $85.31 \%$ \\
Mean & 0 & $54.08 \%$ & $64.29 \%$ & $75.21 \%$ & $86.77 \%$ \\
\hline
\end{tabular}


diameter with Logistic model, to analyze the effects of light intensity and seeding density on the growth rhythm of Liriodendron chinense seedlings. The specific calculation formulas are as follows:

Germination rate:

$$
G_{r}=\frac{G_{a}}{G_{n}} \times 100 \%
$$

Seedling emergence rate:

$$
S R=\frac{G_{s}}{G_{a}} \times 100 \%
$$

wherein " $G$ " represents the number of germinated seeds, " $G_{n}$ " the number of sown seeds, and " $G_{s}$ ” the number of surviving seedlings.

The Logistic model fitted equation is:

$$
y=\frac{k}{1+\mathrm{e}^{a-b t}}
$$

wherein " $y$ " represents the cumulative increment of seedlings, " $k$ " the fitted growth limit value of seedling height, " $l$ " the growth time, and " $a$ " and " $b$ " the undetermined coefficients.

The phenological phase parameters and growth rhythm parameters of Liriodendron chinense seedling height and basal diameter were calculated with the research method of Yang Zhiling et al. [17]. The specific calculation formulas are as follows:

Beginning of linear growth:

$$
t_{1}=\frac{a-1.317}{b}
$$

End of linear growth:

$$
t_{2}=\frac{a+1.317}{b}
$$

Linear growth duration:

$$
L G D=\frac{2 \ln (2+\sqrt{3})}{4}=\frac{2.634}{b}
$$

Maximum linear growth rate:

$$
M G R=v_{\max }=\frac{1}{4} b k
$$

Linear growth rate:

$$
L G R=\frac{2}{9} b k
$$

Linear growth increment:

$$
T L G=\frac{k}{\sqrt{3}}
$$




\section{Results}

\subsection{Effects of Light on the Seed Germination and Seedling Growth of Liriodendron chinense}

As shown in Table 2, light has a significant effect on the seed germination and seedling growth of Liriodendron chinense $(P<0.01)$. The results of further analysis are shown in Figure 1 and Figure 2. The groups treated with shading methods show much higher germination rate, seedling emergence rate and seedling height than the control. Expect for the Liriodendron chinense seedlings treated with 4-stitch and 6-stitch sunshade nets, the seedlings under other light conditions have greater basal diameters than the control, indicating that appropriate shading treatment is conducive to seed germination and seedling height increase of Liriodendron chinense. The seeds treated with 2-stitch sunshade net present the highest germination rate of $5.19 \%$, with no remarkable difference from those treated with 3-stitch, 4-stitch and 6-stitch sunshade nets. The groups treated with 2-stitch and 3-stitch sunshade nets show the highest seedling emergence rates, which are similar to each other and $50.97 \%$ and $30.29 \%$ higher than that of the control. The seedling height of Liriodendron chinense under the condition of the 3-stitch sunshade net is $23.94 \mathrm{~cm}$, an overwhelming superiority, followed by the 6-stitch, 4 -stitch and 2-stitch groups. The seedling height of $\mathrm{CK}$ is notably lower than that of the others. Additionally, the basal diameter of $L i$ riodendron chinense seedlings treated with the 3 -stitch sunshade net is the largest, followed closely by those treated with the 2 -stitch sunshade net, which are $49.64 \%$ and $37.35 \%$ higher than that of the control group. The basal diameters of seedlings treated with the 4-stitch and 6-stitch sunshade nets are the smallest, with little difference between each other. To conclude, among different shading treatments, 2-stitch and 3-stitch sunshade nets are most favorable for the seed germination and seedling growth of Liriodendron chinense.

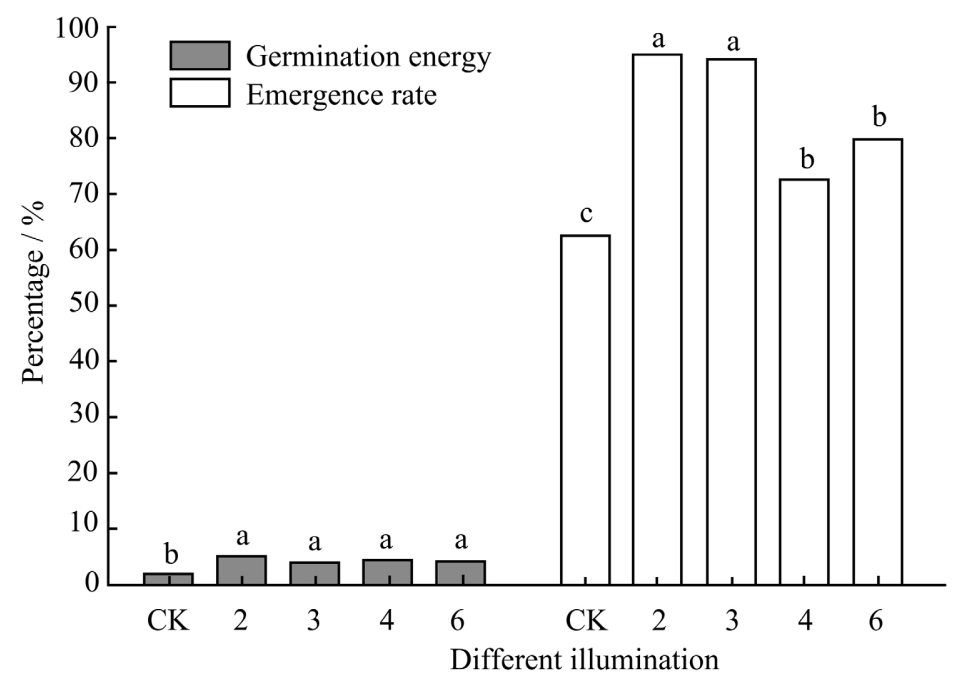

Figure 1. The effect of different light on seed germination of Liriodendron chinense. Note: Different letters indicate significant differences $(P<0.05)$. 


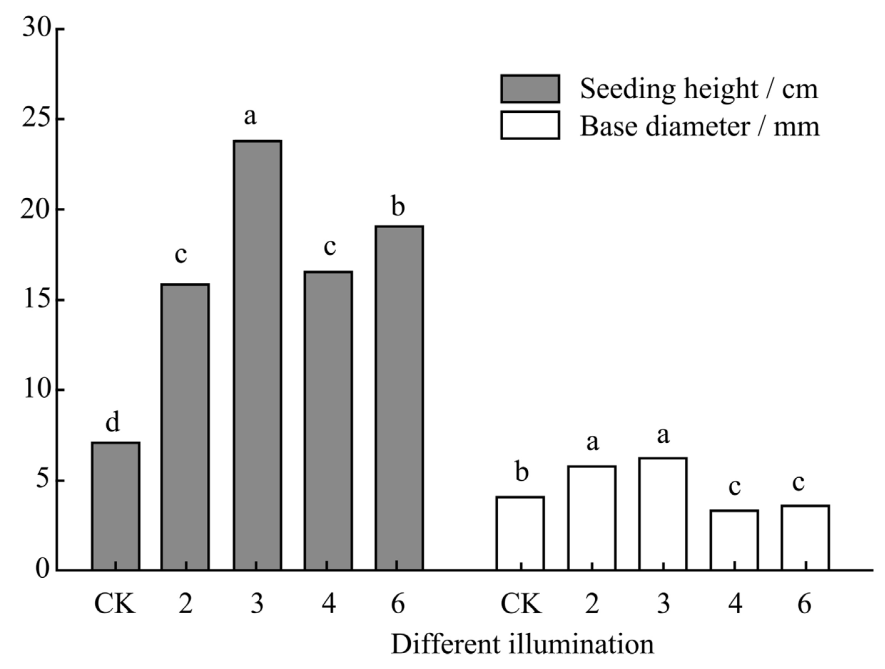

Figure 2. The effect of different light on seedling growth of Liriodendron chinense. Note: Different letters indicate significant differences $(P<0.05)$.

Table 2. Variance analysis of the effects of different light and sowing density on the seed germination and seedling growth of Liriodendron chinense.

\begin{tabular}{ccccc}
\hline Factor & $\begin{array}{c}\text { Germination } \\
\text { rate }\end{array}$ & $\begin{array}{c}\text { Emergence } \\
\text { rate }\end{array}$ & $\begin{array}{c}\text { Seedling } \\
\text { height }\end{array}$ & $\begin{array}{c}\text { Base } \\
\text { diameter }\end{array}$ \\
\hline Illumination & 0.000 & 0.000 & 0.000 & 0.000 \\
Seeding density & 0.625 & 0.000 & 0.000 & 0.000 \\
Illumination $\times$ Seeding density & 0.009 & 0.000 & 0.000 & 0.000 \\
\hline
\end{tabular}

\subsection{Effects of Seeding Density on the Seed Germination and Seedling Growth of Liriodendron chinense}

Seeding density has little relevance with the seed germination rate of Liriodendron chinense $(P>0.05)$, but affects the seedling emergence rate, seedling height and basal diameter of Liriodendron chinense greatly $(P<0.01)$ (Table 2$)$. After further analysis (Figure 3 and Figure 4), it can be seen that the seedling emergence rate of Liriodendron chinense at the seeding density of $400 \mathrm{seeds} / \mathrm{m}^{2}$ is the highest, which is $91.43 \%$, no great discrepancy with those sown at densities of 500 seeds $/ \mathrm{m}^{2}$ and 200 seeds $/ \mathrm{m}^{2}$. The seedling emergence rate of 400 seeds $/ \mathrm{m}^{2}$ is evidently higher than that of 100 seeds $/ \mathrm{m}^{2}$ and 300 seeds $/ \mathrm{m}^{2}$ by $20.14 \%$ and $24.43 \%$. The seedling height shows a rising trend with the increase of seeding density. The seedlings with a seeding density of 500 seeds $/ \mathrm{m}^{2}$ and 400 seeds $/ \mathrm{m}^{2}$ are the highest, $20.68 \mathrm{~cm}$ and $19.18 \mathrm{~cm}, 8.2 \mathrm{~cm}$ and $6.7 \mathrm{~cm}$ higher than those sown at 100 seeds $/ \mathrm{m}^{2}$. The Liriodendron chinense seedlings sown at $100 \mathrm{seeds} / \mathrm{m}^{2}$ show the smallest basal diameter, $30.11 \%, 33.60 \%, 26.08 \%$ and $26.08 \%$ smaller than those sown at $200,300,400$ and 500 seeds $/ \mathrm{m}^{2}$. In conclusion, the seeding densities of 400 and 500 seeds $/ \mathrm{m}^{2}$ are the most favorable for the growth of Liriodendron chinense seedlings, resulting in the greatest seedling emergence rate, seedling height and basal diameter; 100 seeds $/ \mathrm{m}^{2}$ is an unsatisfactory condition for seed germination and seedling growth. 


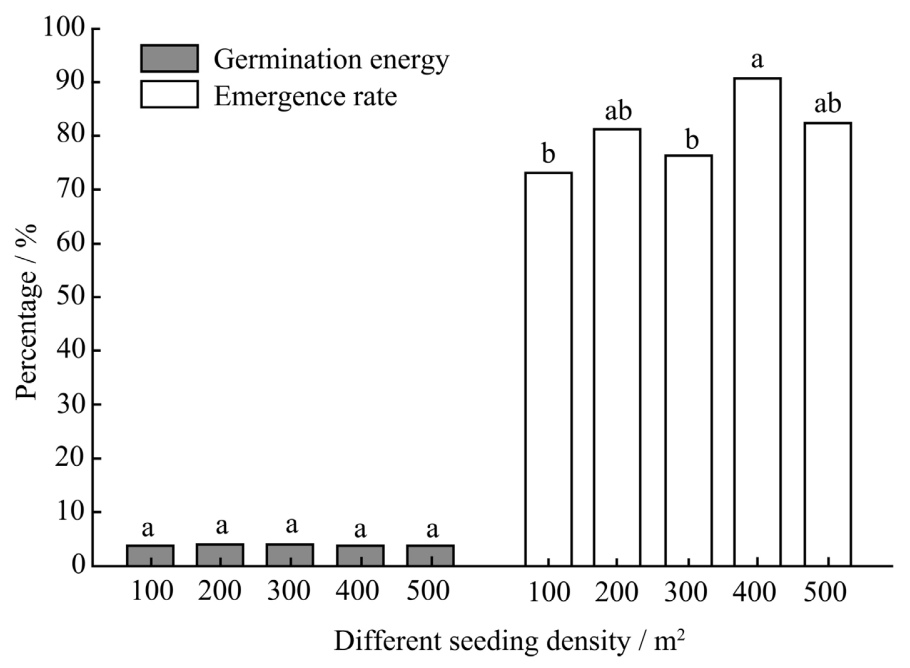

Figure 3. The effects of different planting densities on seed germination of Liriodendron chinense. Note: Different letters indicate significant differences $(P<0.05)$.

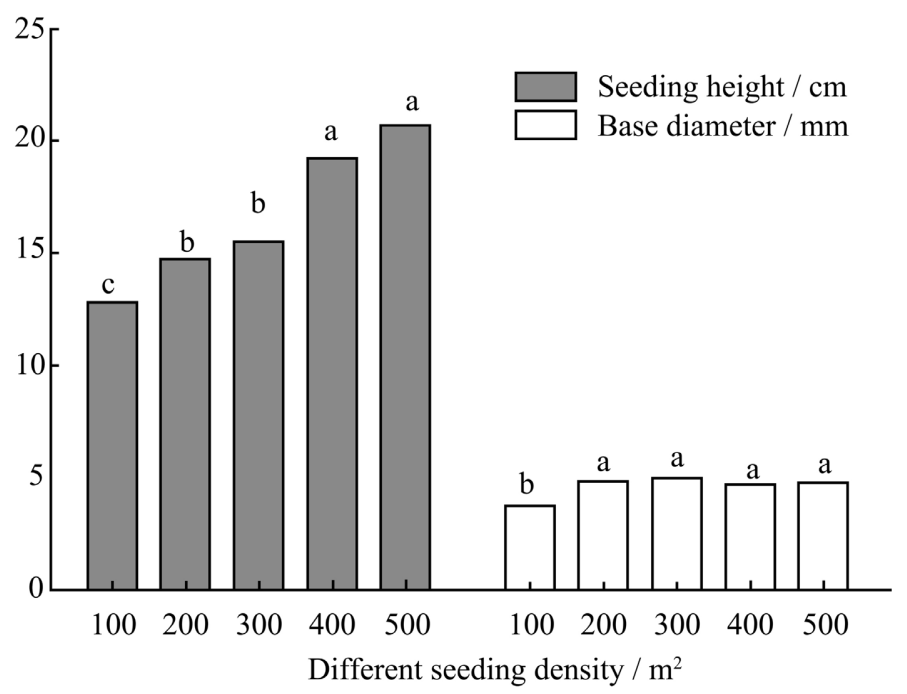

Figure 4. The effects of different planting densities on seedling growth of Liriodendron chinense. Note: Different letters indicate significant differences $(P<0.05)$.

\subsection{Interactive Effects of Light and Seeding Density on Seed Germination and Seedling Growth}

As indicated by Table 2, the interaction between light and seeding density has a great impact on the seed germination rate of Liriodendron chinense $(P<0.05)$, and a highly significant influence on the seedling emergence rate, seedling height and basal diameter $(P<0.01)$. Through further analysis of the various indicators with interactive effects under different treatments, as shown in Table 3 , the seed germination rate is the highest under the condition of " 2 -stitch +200 seeds $/ \mathrm{m}^{2}$ ",

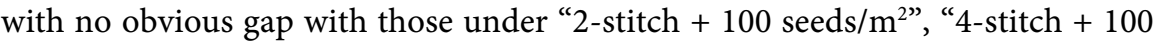

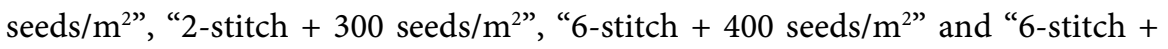
300 seeds $/ \mathrm{m}^{2 "}$; the germination rates under $\mathrm{CK}+100,200$, and 300 seeds $/ \mathrm{m}^{2}$ and under "6-stitch +100 seeds $/ \mathrm{m}^{2 \text { " }}$ are the lowest, with no remarkable difference 
Table 3. Interaction of light and sowing density on seed germination and seedling growth of Liriodendron chinense.

\begin{tabular}{|c|c|c|c|c|}
\hline $\begin{array}{c}\text { Illumination seeding } \\
\text { density level combination }\end{array}$ & $\begin{array}{l}\text { Germination } \\
\text { rate } / \%\end{array}$ & $\begin{array}{c}\text { Emergence } \\
\text { rate } / \%\end{array}$ & $\begin{array}{l}\text { Seedling } \\
\text { height } \%\end{array}$ & $\begin{array}{c}\text { Base } \\
\text { diameter/\% }\end{array}$ \\
\hline $\mathrm{CK}+100 \mathrm{Grain} / \mathrm{m}^{2}$ & $0.33 \mathrm{~g}$ & $0.00 \mathrm{~g}$ & $0.00 \mathrm{~g}$ & $0.00 \mathrm{~g}$ \\
\hline $\mathrm{CK}+200 \mathrm{Grain} / \mathrm{m}^{2}$ & $1.83 \mathrm{fg}$ & $72.22 \mathrm{bcdef}$ & $8.08 \mathrm{n}$ & $4.57 \mathrm{cde}$ \\
\hline $\mathrm{CK}+300 \mathrm{Grain} / \mathrm{m}^{2}$ & $2.11 \mathrm{efg}$ & $76.85 \mathrm{abcdef}$ & $9.25 \operatorname{lmn}$ & $5.88 \mathrm{abc}$ \\
\hline $\mathrm{CK}+400 \mathrm{Grain} / \mathrm{m}^{2}$ & $3.00 \mathrm{cdef}$ & $90.00 \mathrm{abcde}$ & $8.67 \mathrm{mn}$ & $5.30 \mathrm{abc}$ \\
\hline $\mathrm{CK}+500 \mathrm{Grain} / \mathrm{m}^{2}$ & $3.00 \mathrm{cdef}$ & 75.34abcdef & $9.51 \mathrm{lmn}$ & $4.98 \mathrm{bcd}$ \\
\hline 2 Needle +100 Grain $/ \mathrm{m}^{2}$ & $6.67 \mathrm{ab}$ & $96.30 \mathrm{abc}$ & $13.76 \mathrm{ijk}$ & $5.58 \mathrm{abc}$ \\
\hline 2 Needle +200 Grain $/ \mathrm{m}^{2}$ & $7.33 \mathrm{a}$ & $91.36 \mathrm{abcd}$ & $16.25 \mathrm{ghij}$ & $5.87 \mathrm{abc}$ \\
\hline 2 Needle +300 Grain $/ \mathrm{m}^{2}$ & $5.33 \mathrm{abcd}$ & $95.45 \mathrm{abc}$ & $19.06 \mathrm{efg}$ & $6.67 \mathrm{a}$ \\
\hline 2 Needle +400 Grain $/ \mathrm{m}^{2}$ & $3.08 \mathrm{cdef}$ & $93.33 \mathrm{abcd}$ & $11.95 \mathrm{klm}$ & $4.60 \mathrm{cde}$ \\
\hline 2 Needle +500 Grain $/ \mathrm{m}^{2}$ & $3.53 \mathrm{cdef}$ & $98.25 \mathrm{ab}$ & 18.37 efgh & $5.79 \mathrm{abc}$ \\
\hline 3 Needle + 100 Grain $/ \mathrm{m}^{2}$ & $4.30 \mathrm{bcdef}$ & $100.00 \mathrm{a}$ & 17.03fghi & $6.25 \mathrm{ab}$ \\
\hline 3 Needle +200 Grain $/ \mathrm{m}^{2}$ & $4.00 \mathrm{cdef}$ & $96.67 \mathrm{abc}$ & $21.73 \mathrm{cde}$ & $6.45 \mathrm{a}$ \\
\hline 3 Needle +300 Grain $/ \mathrm{m}^{2}$ & $4.67 \mathrm{bcde}$ & $85.12 \mathrm{abcdef}$ & $23.47 \mathrm{~cd}$ & $6.25 \mathrm{ab}$ \\
\hline 3 Needle +400 Grain $/ \mathrm{m}^{2}$ & $4.00 \mathrm{cdef}$ & 93.97abcd & $27.60 \mathrm{ab}$ & $6.33 \mathrm{ab}$ \\
\hline 3 Needle +500 Grain $/ \mathrm{m}^{2}$ & $3.90 \mathrm{cdef}$ & $94.91 \mathrm{abcd}$ & $29.85 \mathrm{a}$ & $5.75 \mathrm{abc}$ \\
\hline 4 Needle +100 Grain $/ \mathrm{m}^{2}$ & $5.67 \mathrm{abc}$ & $71.11 \mathrm{cdef}$ & $13.77 \mathrm{ijk}$ & $3.14 \mathrm{f}$ \\
\hline 4 Needle +200 Grain $/ \mathrm{m}^{2}$ & $4.5 \mathrm{bcdef}$ & 74.60abcdef & $12.55 \mathrm{jkl}$ & $3.43 \mathrm{ef}$ \\
\hline 4 Needle +300 Grain $/ \mathrm{m}^{2}$ & $4.3 \mathrm{bcdef}$ & $63.89 \mathrm{ef}$ & $11.93 \mathrm{klm}$ & $2.81 \mathrm{f}$ \\
\hline 4 Needle +400 Grain $/ \mathrm{m}^{2}$ & $4.08 \mathrm{bcdef}$ & 86.51abcde & $3.47 \mathrm{~cd}$ & $3.58 \mathrm{ef}$ \\
\hline 4 Needle +500 Grain $/ \mathrm{m}^{2}$ & $3.8 \mathrm{cdef}$ & $68.24 \mathrm{edfg}$ & 20.79def & $3.26 \mathrm{ef}$ \\
\hline 6 Needle +100 Grain $/ \mathrm{m}^{2}$ & $2.67 \mathrm{defg}$ & $100.00 \mathrm{a}$ & 17.27fghi & $3.63 \mathrm{ef}$ \\
\hline 6 Needle +200 Grain $/ \mathrm{m}^{2}$ & $4.30 \mathrm{bcdef}$ & $71.16 \mathrm{cdef}$ & 15.09hijk & $3.92 \mathrm{def}$ \\
\hline 6 Needle +300 Grain $/ \mathrm{m}^{2}$ & $4.89 \mathrm{abcd}$ & $59.20 \mathrm{f}$ & 13.77ijk & $3.22 \mathrm{ef}$ \\
\hline 6 Needle +400 Grain $/ \mathrm{m}^{2}$ & $4.92 \mathrm{abcd}$ & $93.34 \mathrm{abcd}$ & $24.23 \mathrm{bcd}$ & $3.66 \mathrm{def}$ \\
\hline 6 Needle +500 Grain $/ \mathrm{m}^{2}$ & $4.73 \mathrm{bcde}$ & 77.54abcdef & $24.85 b c$ & $3.67 \mathrm{def}$ \\
\hline
\end{tabular}

Note: Different letters indicate significant differences $(P<0.05)$.

between each other. The seedling emergence rates under the combined conditions of " 3 -stitch +100 seeds $/ \mathrm{m}^{2 \text { " }}$ and " 6 -stitch +100 seeds $/ \mathrm{m}^{2 \text { " }}$ are the highest,

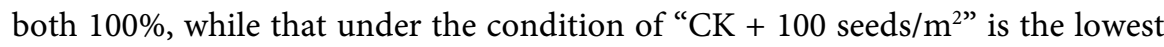
of 0 . At the same time, the seedling height under the condition of " $\mathrm{CK}+100$

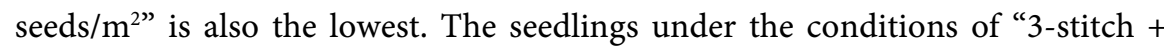
500 seeds $/ \mathrm{m}^{2 \text { " }}$ and " 3 -stitch +400 seeds $/ \mathrm{m}^{2 \text { " }}$ are the highest, $29.85-27.60 \mathrm{~cm}$. The seedlings under the conditions of 2-stitch/3-stitch + different densities and

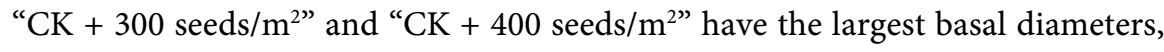




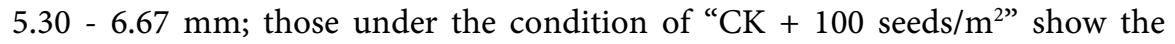
smallest basal diameters. It can be seen that under natural conditions, low density "CK +100 seeds $/ \mathrm{m}^{2 \text { " }}$ is extremely unfavorable for the growth of Liriodendron chinense seedlings; under different density conditions, the 2-stitch and 3 -stitch sunshade net treatments indicate the more satisfactory germination rate, seedling emergence rate, seedling height and basal diameter.

\subsection{Effects of Light and Seeding Density on the Growth Rhythm of Liriodendron chinense Seedlings}

\subsubsection{Effect of Light on the Growth Rhythm of Liriodendron chinense Seedlings}

During the growth of Liriodendron chinense seedlings under different light conditions for one year, the growth rhythm of seedling height and basal diameter accords with the "S" growth curve, so the Logistic mathematical model was used to fit the seedling height and basal diameter of Liriodendron chinense seedlings. According to the data analysis (Table 4 and Table 5), the determination coefficients of the Logistic fitting equation for the seedling height and basal diameter of Liriodendron chinense under different light conditions are $0.977-0.993$ and 0.986 - 0.998 respectively, both of which mark an extreme significant correlation, indicating that the fitted value of the model is highly reliable. The Logistic fitted curves of seedling height and basal diameter under different light conditions are shown in Figure 5 and Figure 6.
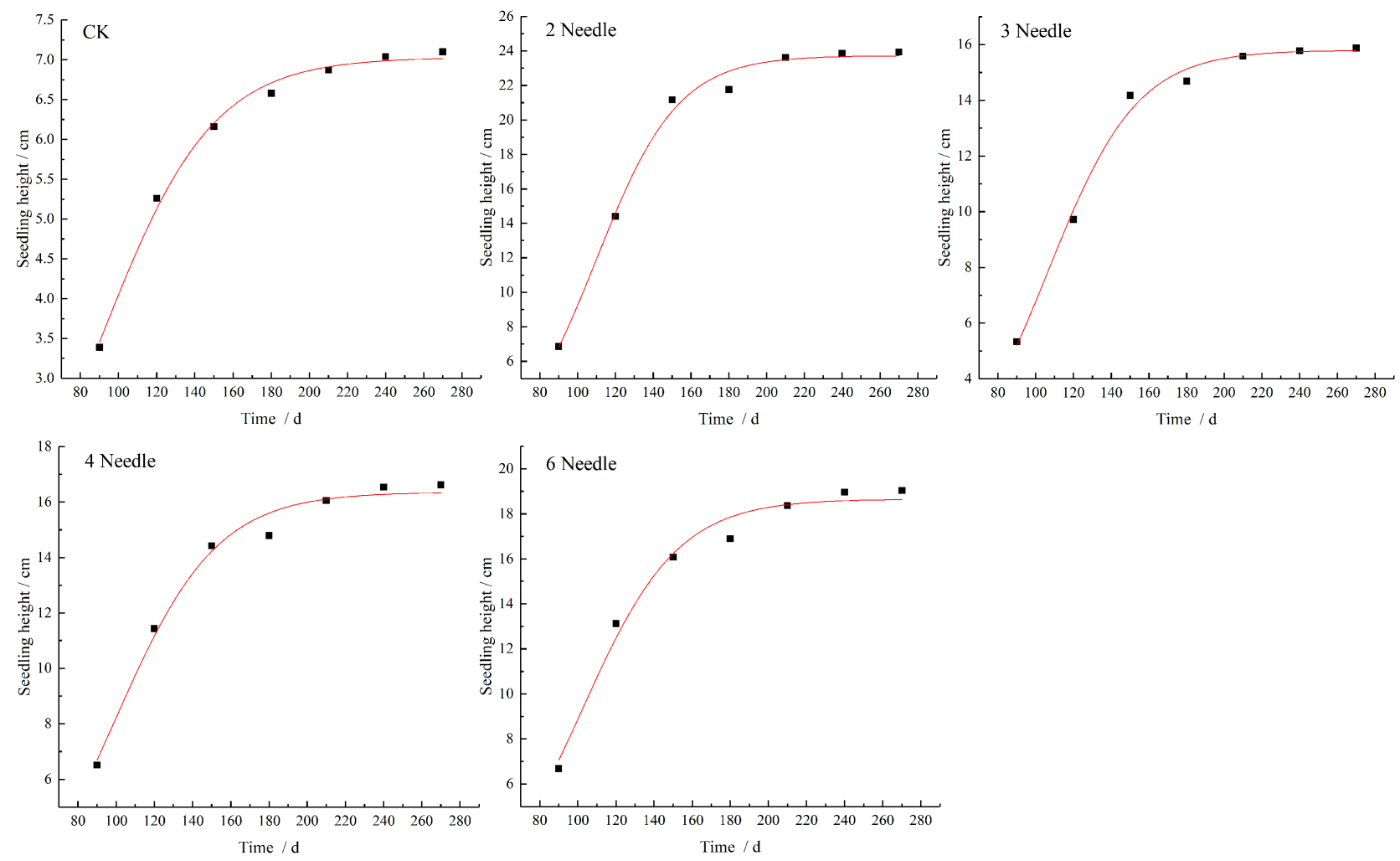

Figure 5. The height growth curve of Liriodendron chinense seedlings under different light conditions. 

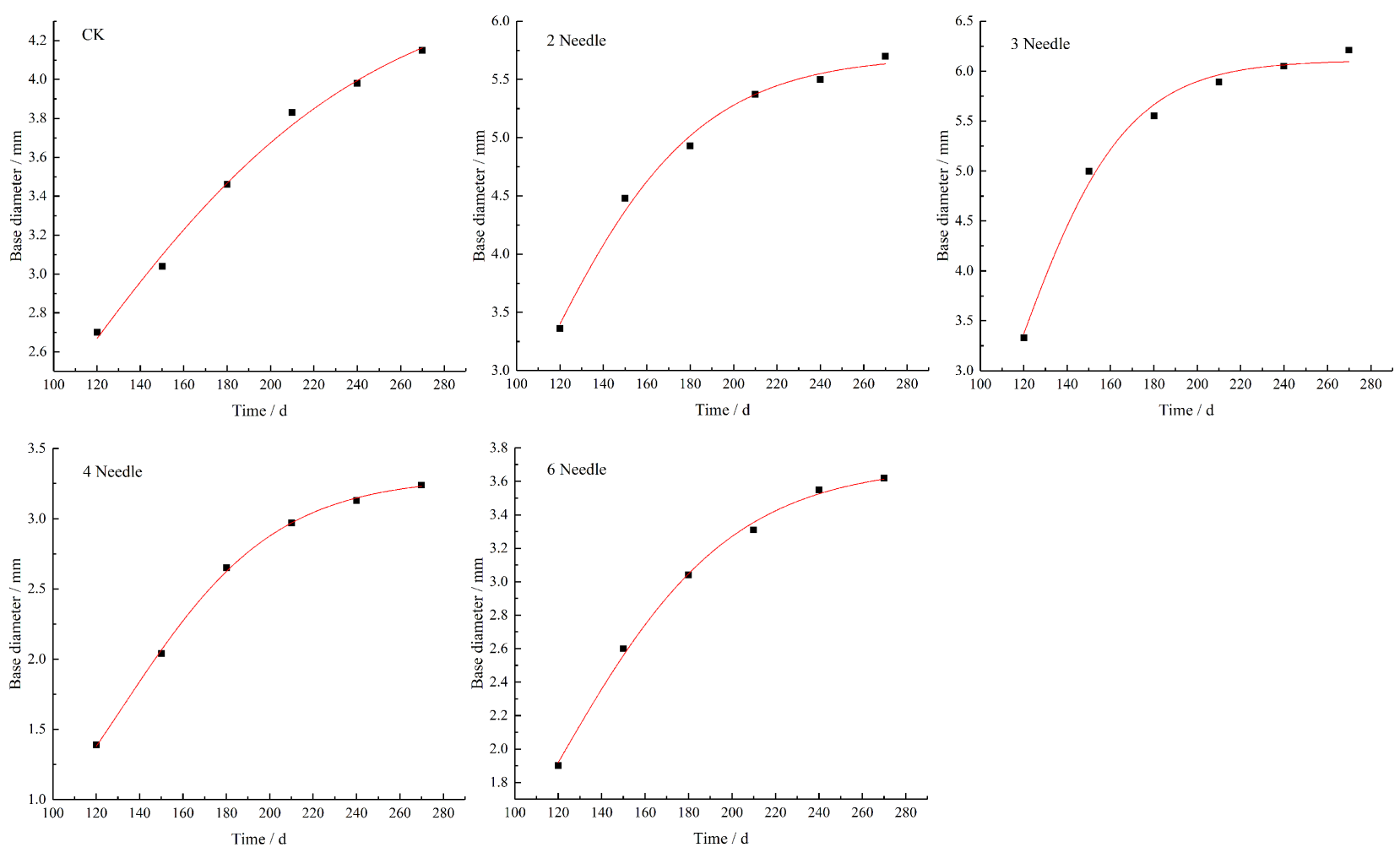

Figure 6. Growth curve of basal diameter of Liriodendron chinense seedlings under different light conditions.

Table 4. Fitting parameters of seedling height growth curve of Liriodendron chinense seedlings with different light intensities.

\begin{tabular}{ccccccc}
\hline \multirow{2}{*}{$\begin{array}{c}\text { Light } \\
\text { gradient }\end{array}$} & $\begin{array}{c}\text { Logistic equation parameters } \\
\text { limitation }(k)\end{array}$ & $\begin{array}{c}\text { Undetermined } \\
\text { coefficient }(a)\end{array}$ & $\begin{array}{c}\text { Undetermined } \\
\text { coefficient }(b)\end{array}$ & $\begin{array}{c}\text { Determination } \\
\text { coefficient }\left(R^{2}\right)\end{array}$ & $\begin{array}{c}\text { Levene } \\
(F)\end{array}$ & $\begin{array}{c}\text { Significant } \\
\text { level }(P)\end{array}$ \\
\hline CK & 7.029 & 3.115 & 0.034 & 0.993 & 6799.026 & $8.65 \times 10^{-8}$ \\
2 Needle & 15.8 & 4.526 & 0.042 & 0.990 & 2704.86 & $5.46 \times 10^{-7}$ \\
3 Needle & 23.725 & 5.034 & 0.046 & 0.989 & 2224.663 & $8.07 \times 10^{-7}$ \\
4 Needle & 16.355 & 3.761 & 0.038 & 0.982 & 1970.999 & $1.03 \times 10^{-6}$ \\
6 Needle & 18.865 & 4.089 & 0.040 & 0.977 & 1338.513 & $2.23 \times 10^{-6}$ \\
\hline
\end{tabular}

Table 5. Fitting parameters of the basal diameter growth curve of Liriodendron chinense seedlings under different light intensities.

\begin{tabular}{ccccccc}
\hline \multirow{2}{*}{$\begin{array}{c}\text { Light } \\
\text { gradient }\end{array}$} & $\begin{array}{c}\text { Gogistic equation parameters } \\
\text { limitation }(k)\end{array}$ & $\begin{array}{c}\text { Undetermined } \\
\text { coefficient }(a)\end{array}$ & $\begin{array}{c}\text { Undetermined } \\
\text { coefficient }(b)\end{array}$ & $\begin{array}{c}\text { Determination } \\
\text { coefficient }\left(R^{2}\right)\end{array}$ & $\begin{array}{c}\text { Levene } \\
(F)\end{array}$ & $\begin{array}{c}\text { Significant } \\
\text { level }(P)\end{array}$ \\
\hline CK & 4.54 & 2.34 & 0.023 & 0.991 & 8679.578 & $2.27 \times 10^{-6}$ \\
2 Needle & 5.704 & 2.8 & 0.027 & 0.988 & 5312.808 & $4.74 \times 10^{-6}$ \\
3 Needle & 6.108 & 4.469 & 0.039 & 0.986 & 3631.549 & $8.39 \times 10^{-6}$ \\
4 Needle & 3.296 & 3.712 & 0.028 & 0.998 & $23,730.768$ & $5.02 \times 10^{-7}$ \\
6 Needle & 3.699 & 2.86 & 0.024 & 0.996 & $11,918.374$ & $1.41 \times 10^{-6}$ \\
\hline
\end{tabular}


As shown in Table 6, the phenological phase parameters of Liriodendron chinense seedling height under different light conditions are different. Specifically, the control group shows the earliest beginning and end of linear growth and the longest linear growth duration; the group treated with the 3-stitch sunshade net is the last to enter the rapid growth period, and to show the beginning of linear growth; the seedlings treated with the 2-stitch sunshade net are the last to show the end of linear growth. The growth parameters of seedling height are also different, presenting a general trend of "increasing, decreasing and rebounding". The maximum linear growth rate, average linear growth rate and linear growth increment are the lowest under the control condition, while those under the 3-stitch sunshade net treatment are the highest, $0.273,0.243$ and $13.698 \mathrm{~cm} / \mathrm{d}$, followed by the group under the 6-stitch sunshade net treatment.

The phenological phase parameters and growth parameters of seedling basal diameter also vary with the light condition (Table 7), which is more obvious in phenological phase parameters than growth parameters. The growth begins first in the group under control condition, followed by those under the 2-stitch, 6-stitch, 3-stitch, and 4-stitch conditions; the group treated with the 4-stitch

Table 6. Seedling height phenological parameters and growth parameters of Liriodendron chinense seedlings under different light intensity.

\begin{tabular}{cccccccc}
\hline & \multicolumn{3}{c}{ Phenological parameters } & \multicolumn{3}{c}{ Growth parameters } \\
\cline { 2 - 8 } $\begin{array}{c}\text { Light } \\
\text { gradient }\end{array}$ & $\begin{array}{c}\text { Early stage of } \\
\text { linear growth } \\
(\mathrm{d})\end{array}$ & $\begin{array}{c}\text { Final stage of } \\
\text { linear growth } \\
(\mathrm{d})\end{array}$ & $\begin{array}{c}\text { Stage of } \\
\text { linear growth } \\
(\mathrm{d})\end{array}$ & $\begin{array}{c}\text { The maximum } \\
\text { linear growth } \\
\text { rate }(\mathrm{cm} / \mathrm{d})\end{array}$ & $\begin{array}{c}\text { Average linear } \\
\text { growth rate } \\
(\mathrm{cm} / \mathrm{d})\end{array}$ & $\begin{array}{c}\text { Quantity of } \\
\text { linear growth } \\
(\mathrm{cm})\end{array}$ & $\begin{array}{c}\text { Linear growth as a } \\
\text { percentage of total } \\
\text { growth }(\%)\end{array}$ \\
\hline CK & 52.882 & 130.353 & 77.471 & 0.060 & 0.053 & 4.058 & $57.16 \%$ \\
2 Needle & 76.405 & 139.119 & 62.714 & 0.166 & 0.147 & 9.122 & $57.44 \%$ \\
3 Needle & 80.804 & 138.065 & 57.261 & 0.273 & 0.243 & 13.698 & $57.22 \%$ \\
4 Needle & 64.316 & 133.632 & 69.316 & 0.155 & 0.138 & 9.443 & $56.81 \%$ \\
6 Needle & 69.300 & 135.150 & 65.850 & 0.189 & 0.168 & 10.892 & $57.20 \%$ \\
\hline
\end{tabular}

Table 7. Seedling height phenological parameters and growth parameters of Liriodendron chinense seedlings under different light intensity.

\begin{tabular}{cccccccc}
\hline & \multicolumn{3}{c}{ Phenological parameters } & \multicolumn{3}{c}{ Growth parameters } \\
\cline { 2 - 8 } $\begin{array}{c}\text { Light } \\
\text { gradient }\end{array}$ & $\begin{array}{c}\text { Early stage of } \\
\text { linear growth } \\
(\mathrm{d})\end{array}$ & $\begin{array}{c}\text { Final stage of } \\
\text { linear growth } \\
(\mathrm{d})\end{array}$ & $\begin{array}{c}\text { Stage of } \\
\text { linear growth } \\
(\mathrm{d})\end{array}$ & $\begin{array}{c}\text { The maximum } \\
\text { linear growth } \\
\text { rate }(\mathrm{cm} / \mathrm{d})\end{array}$ & $\begin{array}{c}\text { Average linear } \\
\text { growth rate } \\
(\mathrm{cm} / \mathrm{d})\end{array}$ & $\begin{array}{c}\text { Quantity of } \\
\text { linear growth } \\
(\mathrm{cm})\end{array}$ & $\begin{array}{c}\text { Linear growth as a } \\
\text { percentage of total } \\
\text { growth }(\%)\end{array}$ \\
\hline CK & 44.478 & 159.000 & 114.522 & 0.026 & 0.023 & 2.621 & $63.16 \%$ \\
2 Needle & 54.926 & 152.481 & 97.556 & 0.039 & 0.034 & 3.293 & $57.78 \%$ \\
3 Needle & 80.821 & 148.359 & 67.538 & 0.060 & 0.053 & 3.526 & $56.79 \%$ \\
4 Needle & 85.536 & 179.607 & 94.071 & 0.023 & 0.021 & 1.903 & $58.73 \%$ \\
6 Needle & 64.292 & 174.042 & 109.750 & 0.022 & 0.020 & 2.136 & $58.99 \%$ \\
\hline
\end{tabular}


sunshade net shows the latest beginning and end of growth, as well as the minimum average linear growth rate and linear growth increment; the control group has the longest linear growth duration. The groups under 3-stitch and 6-stitch shading conditions present the highest and the lowest maximum linear growth rates. In a word, the growth end and linear growth duration of basal diameter are later than those of seedling height, and the growth of basal diameter begins earlier than seedling height under other light conditions except for 3-stitch and 4 -stitch sunshade nets. Within the one year growth cycle of seedling height and basal diameter, and the linear growth increment takes more than $56 \%$ of the total increment.

\subsubsection{Effects of Seeding Density on the Growth Rhythm of Liriodendron chinense Seedlings}

The growth rhythm of seedling height and basal diameter of Liriodendron chinense seedlings under different seeding densities matches the " $\mathrm{S}$ " growth curve. As shown by Table 8 and Table 9 , the determination coefficients of the Logistic fitting equation for the seedling height and basal diameter of Liriodendron chinense under different seeding densities are $0.977-0.996$ and $0.987-0.998$ respectively, both of which mark an extreme significant correlation, indicating that the fitted value of the model is highly reliable. The Logistic fitted curves of seedling height and basal diameter under different seeding densities are shown in Figure 7 and Figure 8.

Table 8. Fitting parameters of seedling height growth curve of Liriodendron chinense seedlings with different seeding densities.

\begin{tabular}{ccccccc}
\hline \multirow{2}{*}{$\begin{array}{c}\text { Planting } \\
\text { density } \\
\left(\text { Grain } / \mathrm{m}^{2}\right)\end{array}$} & $\begin{array}{c}\text { Lrowth } \\
\text { limitation }(k)\end{array}$ & $\begin{array}{c}\text { Undetermined } \\
\text { coefficient }(a)\end{array}$ & $\begin{array}{c}\text { Undetermined } \\
\text { coefficient }(b)\end{array}$ & $\begin{array}{c}\text { Determination } \\
\text { coefficient }\left(R^{2}\right)\end{array}$ & $\begin{array}{c}\text { Levene } \\
(F)\end{array}$ & $\begin{array}{c}\text { Significant } \\
\text { level }(P)\end{array}$ \\
\hline 100 & 12.305 & 4.287 & 0.044 & 0.994 & 6309.886 & $1 \times 10^{-7}$ \\
200 & 14.603 & 4.373 & 0.044 & 0.993 & 5230.736 & $1.46 \times 10^{-7}$ \\
300 & 15.376 & 4.459 & 0.034 & 0.996 & 6679.509 & $8.96 \times 10^{-8}$ \\
400 & 18.838 & 4.402 & 0.041 & 0.977 & 1066.055 & $3.51 \times 10^{-6}$ \\
500 & 20.563 & 4.019 & 0.037 & 0.987 & 1865.069 & $1.15 \times 10^{-6}$ \\
\hline
\end{tabular}

Table 9. Fitting parameters of basal diameter growth curve of Liriodendron chinense seedlings with different seeding densities.

\begin{tabular}{ccccccc}
\hline \multirow{2}{*}{$\begin{array}{c}\text { Planting } \\
\text { density } \\
\left(\text { Grain/m } / \mathrm{m}^{2}\right)\end{array}$} & $\begin{array}{c}\text { Logistic equation parameters } \\
\text { limitation }(k)\end{array}$ & $\begin{array}{c}\text { Undetermined } \\
\text { coefficient }(a)\end{array}$ & $\begin{array}{c}\text { Undetermined } \\
\text { coefficient }(b)\end{array}$ & $\begin{array}{c}\text { Determination } \\
\text { coefficient }\left(R^{2}\right)\end{array}$ & $\begin{array}{c}\text { Levene } \\
(F)\end{array}$ & $\begin{array}{c}\text { Significant } \\
\text { level }(P)\end{array}$ \\
\hline 100 & 3.824 & 2.049 & 0.02 & 0.998 & $42,818.693$ & $2.07 \times 10^{-7}$ \\
200 & 4.863 & 3.224 & 0.028 & 0.989 & 4105.282 & $6.98 \times 10^{-6}$ \\
300 & 4.995 & 3.375 & 0.029 & 0.993 & 6430.8 & $3.56 \times 10^{-6}$ \\
400 & 4.687 & 3.212 & 0.028 & 0.995 & $10,402.851$ & $1.73 \times 10^{-6}$ \\
500 & 4.755 & 2.574 & 0.024 & 0.987 & $16,379.846$ & $8.76 \times 10^{-7}$ \\
\hline
\end{tabular}



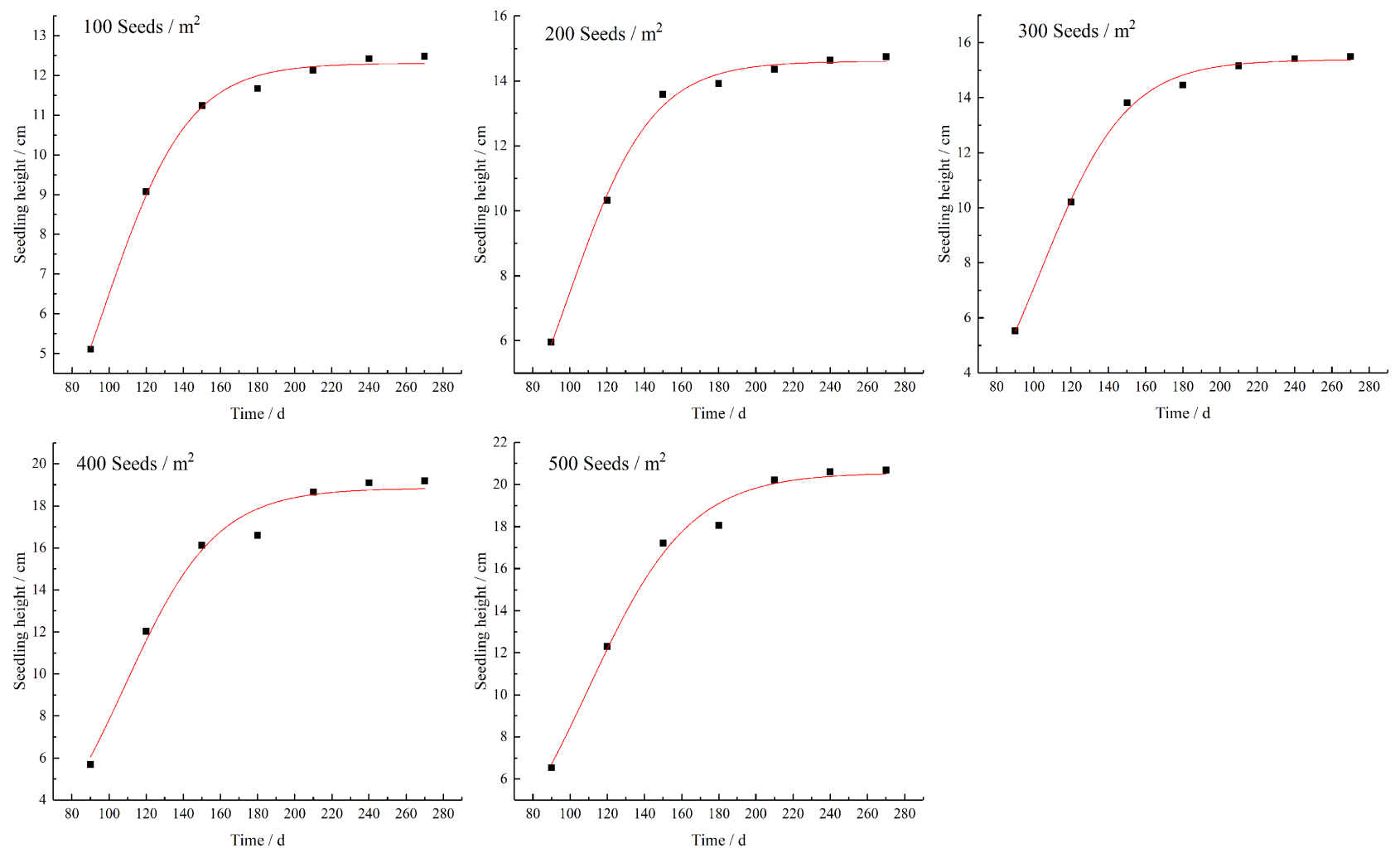

Figure 7. The height growth curve of Liriodendron chinense seedlings under different sowing densities.
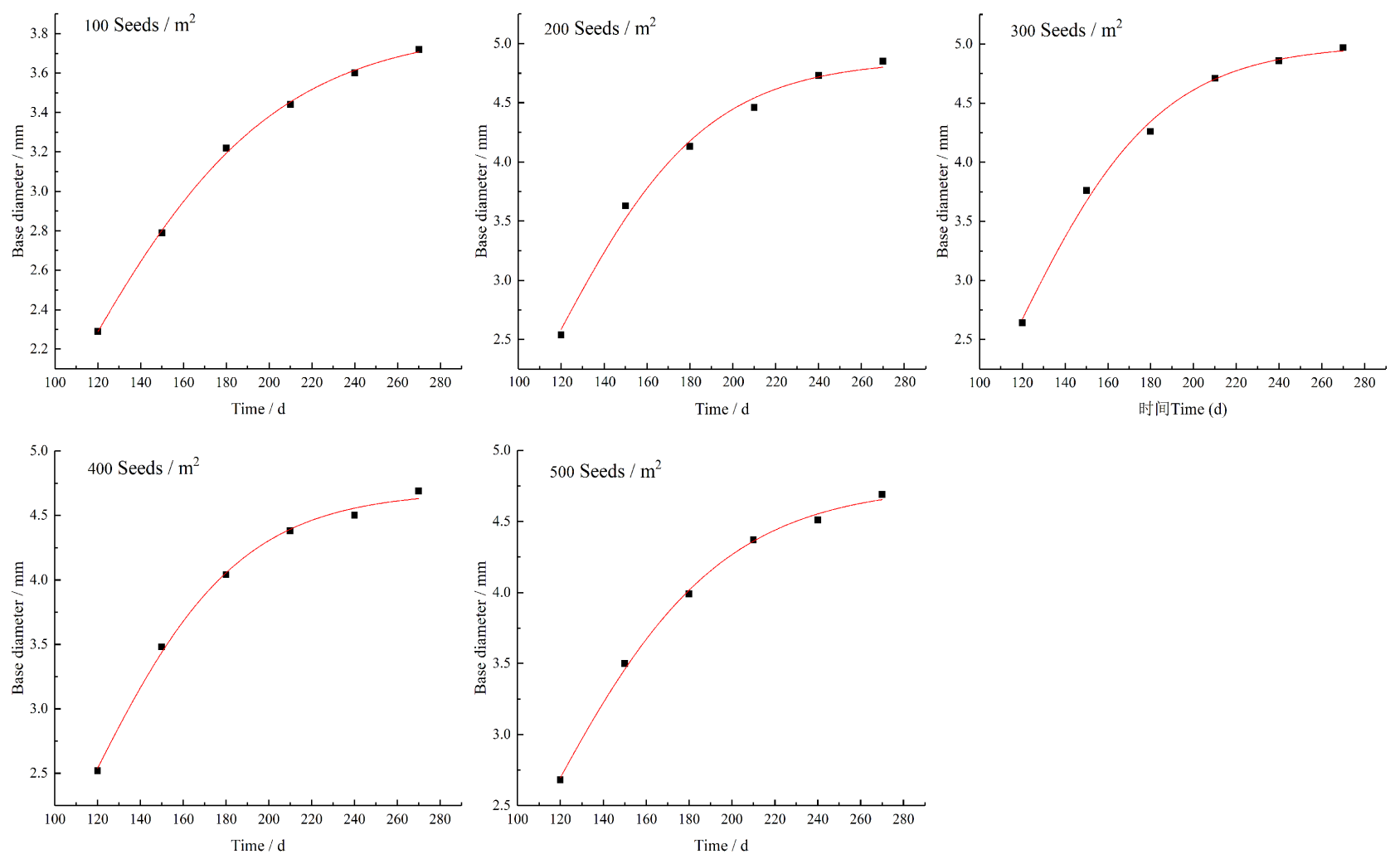

Figure 8. Growth curve of basal diameter of Liriodendron chinense seedlings under different sowing densities. 
It can be seen from Table 10 that the phenological phase parameters of Liriodendron chinense seedling height also vary with the seeding density, which is more obvious in the beginning and end of linear growth than in the linear growth duration. The control group shows the earliest beginning and end of linear growth and the longest linear growth duration; the seedlings under the condition of 300 seeds $/ \mathrm{m}^{2}$ indicate the latest beginning and end of seedling height linear growth and the longest linear growth duration of seedling height. The growth parameters of seedling height are also discrepant. The maximum linear growth rate, average linear growth rate and the percentage of linear growth increment in the total increment present an "increasing, decreasing and rebounding" curve; the linear growth increment is the lowest in the control, and moves up with the increase of the seeding density. The percentage of linear growth increment in the total increment is the lowest (56.71\%) under the condition of 400 seeds $/ \mathrm{m}^{2}$, while the highest under 500 seeds $/ \mathrm{m}^{2}$, followed by 300 seeds $/ \mathrm{m}^{2}, 400$ seeds $/ \mathrm{m}^{2}$ and the control.

There are also disparities in the phenological phase parameters and growth parameters of the basal diameter of Liriodendron chinense seedlings. According to the results shown in Table 11, the beginning and end of linear growth display

Table 10. Seedling height phenological parameters and growth parameters of Liriodendron chinense seedlings with different seeding densities.

\begin{tabular}{|c|c|c|c|c|c|c|c|}
\hline \multirow{2}{*}{$\begin{array}{c}\text { Planting } \\
\text { density } \\
\left(\text { Grain } / \mathrm{m}^{2}\right)\end{array}$} & \multicolumn{3}{|c|}{ Phenological parameters } & \multicolumn{4}{|c|}{ Growth parameters } \\
\hline & $\begin{array}{l}\text { Early stage of } \\
\text { linear growth } \\
\text { (d) }\end{array}$ & $\begin{array}{l}\text { Final stage of } \\
\text { linear growth } \\
\text { (d) }\end{array}$ & $\begin{array}{l}\text { Stage of } \\
\text { linear growth } \\
\text { (d) }\end{array}$ & $\begin{array}{l}\text { The maximum } \\
\text { linear growth } \\
\text { rate }(\mathrm{cm} / \mathrm{d})\end{array}$ & $\begin{array}{l}\text { Average linear } \\
\text { growth rate } \\
(\mathrm{cm} / \mathrm{d})\end{array}$ & $\begin{array}{l}\text { Quantity of } \\
\text { linear growth } \\
(\mathrm{cm})\end{array}$ & $\begin{array}{c}\text { Linear growth as a } \\
\text { percentage of total } \\
\text { growth (\%) }\end{array}$ \\
\hline 100 & 67.500 & 127.364 & 59.864 & 0.135 & 0.120 & 7.104 & $56.93 \%$ \\
\hline 200 & 69.455 & 129.318 & 59.864 & 0.161 & 0.143 & 8.431 & $57.20 \%$ \\
\hline 300 & 92.412 & 169.882 & 77.471 & 0.131 & 0.116 & 8.877 & $57.27 \%$ \\
\hline 400 & 75.244 & 139.488 & 64.244 & 0.193 & 0.172 & 10.876 & $56.71 \%$ \\
\hline 500 & 73.027 & 144.216 & 71.189 & 0.190 & 0.169 & 11.872 & $57.41 \%$ \\
\hline
\end{tabular}

Table 11. Phenological parameters and growth parameters of base diameter of Liriodendron chinense seedlings with different seeding densities.

\begin{tabular}{cccccccc}
\hline \multirow{2}{*}{$\begin{array}{c}\text { Planting } \\
\text { density } \\
\left(\mathrm{Grain} / \mathrm{m}^{2}\right)\end{array}$} & $\begin{array}{c}\text { Early stage of } \\
\text { linear growth } \\
(\mathrm{d})\end{array}$ & $\begin{array}{c}\text { Final stage of } \\
\text { linear growth } \\
(\mathrm{d})\end{array}$ & $\begin{array}{c}\text { Stage of linear } \\
\text { growth } \\
(\mathrm{d})\end{array}$ & $\begin{array}{c}\text { The maximum } \\
\text { linear growth } \\
\text { rate }(\mathrm{cm} / \mathrm{d})\end{array}$ & $\begin{array}{c}\text { Average linear } \\
\text { growth rate } \\
(\mathrm{cm} / \mathrm{d})\end{array}$ & $\begin{array}{c}\text { Quantity of } \\
\text { linear growth } \\
(\mathrm{cm})\end{array}$ & $\begin{array}{c}\text { Linear growth as a } \\
\text { percentage of total } \\
\text { growth }(\%)\end{array}$ \\
\hline 100 & 36.600 & 168.300 & 131.700 & 0.019 & 0.017 & 2.208 & $59.35 \%$ \\
200 & 68.107 & 162.179 & 94.071 & 0.034 & 0.030 & 2.808 & $57.89 \%$ \\
300 & 70.966 & 161.793 & 90.828 & 0.036 & 0.032 & 2.884 & $58.03 \%$ \\
400 & 67.679 & 161.750 & 94.071 & 0.033 & 0.029 & 2.706 & $57.70 \%$ \\
500 & 52.375 & 162.125 & 109.750 & 0.029 & 0.025 & 2.745 & $58.54 \%$ \\
\hline
\end{tabular}


the greatest gaps. The control group presents the earliest beginning and the latest end of linear growth, and consequently the longest linear growth duration (131.7 d); the lowest maximum linear growth rate, average linear growth rate and linear growth increment; and the largest percentage of linear growth increment in the total increment (59.35\%). The group under the condition of $300 \mathrm{seeds} / \mathrm{m}^{2}$ bears the latest beginning of linear growth, and the highest maximum linear growth rate, average linear growth rate and linear growth increment. The group under the condition of 400 seeds $/ \mathrm{m}^{2}$ gets the lowest percentage (57.7\%) of linear growth increment in the total increment, and the group under 200 seeds $/ \mathrm{m}^{2}$ shows the earliest end of linear growth. In conclusion, the basal diameter begins to grow earlier than seedling height, and enjoys a longer linear growth duration than the latter. Except for the $300 \mathrm{seeds} / \mathrm{m}^{2}$ groups, the basal diameter stops growing later than the seedling height. Within the one year growth cycle of seedling height and basal diameter, and the linear growth increment takes more than $56 \%$ of the total increment.

\section{Discussion}

Light, as an important environmental factor for the growth and development, reproduction and regeneration and population succession of plants, has a great impact on the whole life cycle of plants from seed germination to death [18] [19]. The period from seed germination to seedling establishment marks the most sensitive growth stage of plants, and the early growth of seedlings has a direct influence on their development into saplings [20]. An appropriate shading treatment is conducive to seed germination and early seedling growth [21]. According to the results of this study, light has a remarkable impact on Liriodendron chinense seed germination and seedling growth. The maximum linear growth rate, average linear growth rate and linear growth increment are the lowest under natural light, while the highest under the condition of 3-stitch sunshade net. Appropriate shading treatment promotes seed germination and seedling height growth of Liriodendron chinense, and among different shading treatments, the 2-stitch and 3-stitch sunshade nets provide the most beneficial light intensity for the seed germination and seedling growth of Liriodendron chinense. On the whole, compared with the natural light of the control group, the seedlings under shading treatment show smaller basal diameters and greater height, which echoes the research result of Chen Zhanghe, Xue Silei et al., that is, under weak light condition, the plants will have greater vertical growth than horizontal to obtain more light [22] [23]. It proves that shading can promote the growth of seedling height, but not the growth of basal diameter.

Density affects the growth of plants by influencing the utilization of aboveground light and underground organic nutrients by the plants, and changing the competition among individuals [24]. By analyzing the effects of seeding density on the seed germination and seedling growth of Liriodendron chinense, it is found that the seed germination rate of Liriodendron chinense is generally low 
due to its reproductive characteristics, and won't be improved by increasing seeding density. However, it is clear that higher seeding density can notably enhance the number of sprouted seeds and a greater sowing number will lead to a higher seedling emergence rate in practice. The seeding density is closely related to the growth of seedling height, as manifested by the rising seedling height with the increase of seeding density, and has little effect on the growth of basal diameter, similar to the research results of Wang Guohua et al. [25] and Zhu Shiming et al. [26]. As for the effect of density on seedling growth rhythm, the linear growth increment of seedling height expands with the lifting of density, while the linear growth increment of basal diameter expands with the increase of density before shrinking. After a comprehensive analysis of the interactive effects of light intensity and seeding density on the seed germination and seedling growth of Liriodendron chinense, it can be seen that the condition of " 3 -stitch + 300 seeds $/ \mathrm{m}^{2 \prime}$ can result in greater germination rate and seedling growth. It is the best reference condition for artificially promoting the natural regeneration and reproduction of Liriodendron chinense, and a reasonable reference standard for artificial seeding of Liriodendron chinense.

\section{Conclusion}

During the artificial promotion of natural regeneration of Liriodendron chinense, higher seed density will effectively boost the germination of seeds, and appropriate shading treatment can greatly promote the seed germination rate and the growth of seedlings. In the process of seedling establishment, appropriate fertilization, weeding and other cultivation measures shall be carried out to improve the survival rate of seedlings, according to the growth rhythm of seedlings and the environmental conditions.

\section{Conflicts of Interest}

The authors declare no conflicts of interest regarding the publication of this paper.

\section{References}

[1] He, S.A. and Hao, R.M. (1999) Study on the Natural Population and the Endangering Habitat of Liriodendron chinense in China. Acta Phytoecologica Sinica, 23, 87-95.

[2] He, S.A., Hao, R.M., Tang, S.J., Momohara, A., Mu, J. and Robertson, K. (1996) A Study on the Ecological Factors of Endangering Mechanism of Liriodendron chinense (Hemsl.) Sarg. Journal of Plant Resources and Environment, 5, 2112-2119.

[3] Zhou, R.A. (2012) Seedling Technology of Liriodendron chinense. Anhui Agricultural Science Bulletin, 18, 163-164.

[4] Guan, X.M. (2020) Seedling Technology of Liriodendron chinense in Southern Anhui Mountains. Modern Agricultural Science and Technology, 22, 129-130.

[5] Zhang, H.L. (2020) Study on Seed Seedling and Mountain Afforestation Techniques of Liriodendron chinense. South China Agriculture, 14, 72-73. 
[6] Zhang, C.H., Jiang, H., Bai, T.D., Zhang, L.-Z., Wei, G.-Y. And Huang, S.-X. (2020) Early Growth Performance of Liriodendron chinense Form 5 Provenances in Guangxi. Journal of Northwest Forestry University, 35, 121-128.

[7] Guo, X. (2014) Research Advances on Rooting Influencing Factors of Cutting Propagation of Liriodendron chinense. Anhui Agricultural Science Bulletin, 42, 12964+ 12984.

[8] Zhang, F.Y. and Zhao, Y. (2006) A Study on Cutting Techniques of Liriodendron chinense. Journal of Yunnan Agricultural University, 1, 127-129.

[9] Li, K.Q., Chen, L., Feng, Y.H., et al. (2014) High Genetic Diversity but Limited Gene Flow Among Remnant and Fragmented Natural Populations of Liriodendron chinense Sarg. Biochemical Systematics and Ecology, 54, 230-236. https://doi.org/10.1016/j.bse.2014.01.019

[10] Yao, J., Li, H., Ye, J. And Shi, L. (2016) Relationship between Parental Genetic Distance and off Spring's Heterosis for Early Growth Traits in Liriodendron: Implication for Parent Pair Selection in Cross Breeding. New Forests, 47, 163-177. https://doi.org/10.1007/s11056-015-9508-2

[11] Zhang, M., Zhu, J.J. and Yan, Q.L. (2012) Review on Influence Mechanisms of Light in seed Germination. Chinese Journal of Plant Ecology, 36, 899-908. https://doi.org/10.3724/SP.J.1258.2012.00899

[12] Liu, Q.Q., Huang, Z.J., Guo, S., Wang, D., Wang, C., Wang, Z., et al. (2019) Responses of Seed Germination and Seedling Growth of Cunninghamia lanceolata and Schimasuperba to Different Light Intensities. Chinese Journal of Applied Ecology, 30, 2955-2936.

[13] Wang, Q.L., Qu, B., Mi, J.J., Xu, Y.F. and Shao, M. (2020) The Effect of Temperature on Seed Germination and Seedling Growth of Two Invasive Plants in Rorippa. Biotechnology Journal International, 8, 39-48. https://doi.org/10.9734/bji/2020/v24i530116

[14] Jarboui, R., Dhouib, B. and Ammar, E. (2021) Effect of Food Waste Compost (FWC) and Its Non-Aerated Fermented Extract (NFCE) on Seeds Germination and Plant Growth. Open Journal of Soil Science, 11, 122-138. https://doi.org/10.4236/ojss.2021.112007

[15] Fan, Y.K., Wang, L., Su, T. and Lan, Q.Y. (2020) Spring Drought as a Possible Cause for Disappearance of Native Metasequoia in Yunnan Province, China: Evidence from Seed Germination and Seedling Growth. Global Ecology and Conservation, 22, Article ID: e00912. https://doi.org/10.1016/j.gecco.2020.e00912

[16] Cai, J., Zhang, T., Liu, C., Zhang, Q.R., Guo, Y.J. and Yang, X.Y. (2013) Synopsis of Technical Standards for Collecting Seeds from Wild Plants. Plant Diversity and Resources, 35, 221-233.

[17] Yang, Z.L., Yang, X., Tan, Z.F., Shu, X., Wang, J. and Tan, G.Y. (2011) Simulating Growth Model of Different Magnolia Officinalis Provenances at Seedling Stage. Journal of Northwest A\&F University (Natural Science Edition), 39, 60-68.

[18] Liu, C., Tian, T., Li, S., Wang, F. and Liang, Y. (2018) Growth Response of Chinese Woody Plant Seedlings to Different Light Intensities. Acta Ecologica Sinica, 38, 518 527. https://doi.org/10.5846/stxb201611012221

[19] Callahan, D.M., Munday, J.N. and Atwater, H.A. (2012) Solar Cell Light Trapping Beyond the Ray Optic Limit. Nano Letters, 12, 214-218. https://doi.org/10.1021/nl203351k

[20] Yan, X.F., Zhou, L.B., Li, J., et al. (2010) Effects of Shading on Seed Germination and Seedling Growth of Schizonepeta chinensis. Jiangsu Aericultural Sciences, 4, 
176-179. https://doi.org/10.15889/j.issn.1002-1302.2010.04.102

[21] Yan, X.F. and Cao, M. (2007) Effects of Shading Treatmentson the Growth of Pometia tomentosa Seedlings. Journal of Tropical and Subtropical Botany, 6, 465-472.

[22] Chen, Z.H. and Zhang, D.M. (1999) Seed Germination and Seedling Growth of 24 tree Species in Lower Subtropical Forest. Journal of Tropical and Subtropical Bota$n y, 7,37-46$.

[23] Xue, S.L., Wang, Q.C., Sun, X.X., et al. (2012) Effects of Shading on the Photosynthetic Characteristic, Growt, and Biomass Allocation in Fraxinus mandshurica and Quercus mongolica. Bulletin of Botanical Research, 32, 354-359.

[24] Xue, L. and Fu, J.D. (2012) A Review on Factors Affecting Plant Competition. Journal of Central South University of Forestry \& Technology, 32, 6-15.

[25] Wang, G.H. and Zhao, W.Z. (2015) Effcets of Seed Density on the Germination and Seeding Growth of Haloxylon ammodendron. Journal of Desert Research, 35, 1248 1253.

[26] Zhu, S.M., Xiao, L.L., Xue, L., He, X. Wang, X.D. and Hu, T.C. (2015) Effects of Planting Density on Growth and Biomass of Michelia chapensis Seedlings. Journal of Central South University of Forestry \& Technology, 35, 77-80. 